\title{
ObJetos EN EL ESPACIO DOMÉSTICO: MATERIALIDADES, SUJETOS Y PRÁCTICAS EN LA NOVELÍSTICA DE TomÁs GonZÁlEZ*
}

\footnotetext{
* Artículo derivado de la tesis de maestría "El espacio doméstico en la novelística de Tomás González: prácticas y materialidades", presentada en 2019 al Instituto de Estética de la Pontifica Universidad Católica de Chile para optar al título de Magíster en Estéticas Americanas.
}

Cómo citar este artículo: Ramírez López, W. A. (2021). Objetos en el espacio doméstico: materialidades, sujetos y prácticas en la novelística de Tomás González. Estudios de Literatura Colombiana 48, pp. 281-298. DOI: https://doi.org/10.17533/udea.elc.n48a17

${ }^{1}$ https://orcid.org/0000-0001-8441-3889 wnramirez@uc.cl

Pontificia Universidad Católica de Chile, Chile

Editores: Andrés Vergara Aguirre, Christian Benavides Martínez, Valentina Noreña Gómez

Recibido: 15.08 .2020

Aprobado: 31.10 .2020

Publicado: 18.12 .2020

Copyright: (02021 Estudios de Literatura Colombiana Este es un artí́culo de acceso abierto distribuido bajo los términos de la Licencia Creative Commons AtribuciónNo comercial - Compartir igual 4.0 Internacional

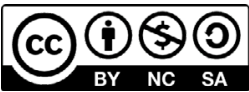

\author{
Objects in Domestic Space: \\ Materialities, Subjects and Practices \\ in the Novels of Tomás GonzÁlez
}

Wilmar A. Ramírez López ${ }^{1}$

Resumen: el presente artículo analiza algunos de los objetos presentes en la novelística de Tomás González. Específicamente, se enfoca en los modos en que los objetos articulan, y se articulan, en relación con unas subjetividades y unas prácticas particulares. Este trabajo dialoga con diversos abordajes interdisciplinarios sobre los objetos, como los hechos por A. Moles, G. Dorfles, M. Perrot y W. Benjamin, entre otros. De esta forma, el análisis expone la intencionalidad de González de ampliar el régimen categorial de los objetos más allá del imperio de su funcionalidad y acumulación hacia un régimen de visibilidad constituido sensible y afectivamente.

Palabras clave: espacio doméstico; objetos; Tomás González; prácticas de lectura; coleccionismo.

Abstract: The aim of this paper is to carry out a general analysis of some objects that appear in the novels of Tomás González. Specifically, this work focuses on the way that the objects operate and are formed in relation to subjectivities and specific practices. In this sense, this analysis interacts with several interdisciplinary approaches about the objects, such as the ones developed by A. Moles, G. Dorfles, M. Perrot and W. Benjamin, among others. Thus, this analysis demonstrates González's intention of expanding the objects categorial regime beyond the functionality domain and accumulation toward a regime of visibility constituted sensitively and affectively.

Keywords: Domestic Space; Objects; Tomás González; Reading practices; Collecting. 


\section{Introducción}

El presente análisis, como parte de una investigación mayor, recoge una aproximación específica al espacio doméstico en seis novelas de Tomás González. ${ }^{1}$ Particularmente, este trabajo se enfoca en los modos en que la modulación material de los objetos, circunscritos a la espacialidad doméstica, reescriben en González las formas de entender el estatus mismo de lo objetual y permiten articular unas prácticas subjetivas que irrumpen en el marco cultural en el que se inscribe la narrativa del autor.

El análisis que aquí se presenta sobre la objetualidad material se basa principalmente en una interpretación de los objetos desde su interacción con los sujetos y las relaciones sociales que allí se establecen, sin pretender con esto desconocer la validez e importancia de otras perspectivas teóricas de análisis de los objetos, que han tomado fuerza en los estudios de la llamada cultura material. En este campo de pensamiento de lo material, algunos enfoques como el del nuevo materialismo han reconocido la autonomía de los objetos y a partir de allí han problematizado su agencia más allá del estatuto de lo antropocéntrico. Del mismo modo, en este espacio conceptual se pueden encontrar otros enfoques como el del materialismo transcultural propuesto por Héctor Hoyos, el cual integra en el marco de la literatura dos de las principales perspectivas de aproximación a la materialidad, esto es, el materialismo histórico y los nuevos materialismos. En línea con estos debates teóricos, el presente análisis, si bien prioriza el vínculo materialidad-subjetividad, dialoga de manera abierta con estos otros enfoques para buscar una interpretación más integral de la realidad material representada en el corpus novelar seleccionado de este escritor colombiano.

Tomás González (1950) cuenta con una amplia trayectoria literaria de casi cuatro décadas, que data de su primera novela, Primero estaba el mar, publicada en 1983. En su producción literaria, hasta la fecha, se cuentan un total de diez novelas, un poemario y cuatro libros de cuentos. Esta larga y diversa trayectoria del autor da cuenta de la versatilidad y diversidad de su escritura. Sin embargo, su posicionamiento en el ámbito de las letras colombianas se dio de manera paulatina a partir del año 2000, pues sería para esa época que su obra comenzaría a llamar la atención de

1 Este análisis se enfoca en seis de las diez novelas publicadas hasta la fecha por Tomás González. Estas son: Primero estaba el mar (1983), Para antes del olvido (1987), La historia de Horacio (2000), Los caballitos del diablo (2003), Abraham entre los bandidos (2010) y Temporal (2012). 
la crítica periodística, ${ }^{2}$ consolidándose de manera definitiva a partir del 2010. Esto último gracias no solo a su prolífica producción literaria del último tiempo, sino también al surgimiento de una amplia producción crítica y académica sobre su obra.

\section{Perderse en los objetos}

El espacio doméstico es el espacio asociado a la casa, al domus, en el que se agrupan las prácticas cotidianas vinculadas con la vida privada y la individualidad de los sujetos. Estas prácticas, configuradoras del sentido de dicho espacio, se estructuran a partir de los ritmos del habitar humano y objetual. En este sentido, dicho espacio es un lugar por excelencia para la cristalización de procesos sociales, políticos y culturales, ya que, como lugar primigenio de habitación, el sujeto despliega en él los procesos a los cuales está vinculado individual y colectivamente. El espacio doméstico es un espacio de significación cuyo estudio permite poner en relato complejas tramas socioculturales que se evidencian a través de su articulación práctica y material.

En línea con lo anterior, se entienden los objetos, junto a las prácticas y las acciones de los sujetos, de acuerdo con lo planteado por Milton Santos (2000, p. 18), como los principales elementos estructurantes del espacio. En la vida contemporánea los objetos se han constituido como uno de los principales ejes articuladores de la realidad social e individual de los sujetos no solo por la usabilidad y los beneficios que esta conlleva, sino también por las significaciones que se asocian a cada uno de ellos en determinados momentos de la historia. Los objetos operan en una doble vía, como signos que cargan semánticamente la existencia de los sujetos espacial, social y psicológicamente; y como agentes materiales autónomos.

La relevancia de los objetos en la época actual se debe a su desmesurada proliferación, producto de la consolidación de una producción industrial y del proceso de flexibilización del mercado global. Los desarrollos productivos del último medio siglo han terminado por inundar el mundo contemporáneo con multiplicidad de objetos, dotados con infinidad de funcionalidades, diseños y significaciones sociales. Esta omnipresencia objetual puso los objetos en el centro de la investigación social, pues se hizo necesario comprender los impactos socioculturales de esta expansión

2 Entre los trabajos sobre González que aparecieron en aquella época destacan las entrevistas realizadas por Ana María Cano: "Primero estaba Medellín” (2001) y “Tomás González la voz de la memoria” (2003). Además, el trabajo de Ignacio Piedrahíta: “Tomás González o el hábito de ser independiente” (2004), en el que se extiende una mirada general sobre la obra del autor publicada hasta entonces. 
material. En este sentido, destacan trabajos de teóricos como Abraham Moles, Jean Baudrillard o Gillo Dorfles, que desde finales de la década del sesenta problematizaron las implicaciones de la materialidad objetual en la realidad social y representacional, pues, como señala este último, en la época moderna los objetos adquirieron tanta importancia como la naturaleza misma (Dorfles, 1972, p. 12).

En su trabajo "Objeto y comunicación”, Abraham Moles (1971) sostiene que el objeto en la cotidianidad es un vector de comunicaciones, un elemento de cultura que representa "la concretización de un gran número de acciones del hombre en la sociedad y se inscribe en la categoría de los mensajes que el medio social envía al individuo o, recíprocamente, que el Homo Faber aporta a la sociedad global” (p. 10). Los objetos comunican multiplicidad de significaciones, que se articulan, por una parte, desde sus modos de producción, sus diseños, sus funcionalidades, sus usos; y por otra, desde los valores emocionales y simbólicos que a ellos atribuyen los sujetos que forman parte de una cultura. En esta pluralidad semiótica radica su relevancia en el marco de la cotidianidad contemporánea.

El espacio doméstico, espacio central para la expresión de la individualidad de los sujetos, está especialmente cargado de objetos que como marcas del habitar estructuran y sostienen la vida cotidiana. A esto alude Michel de Certeau y Luce Giard (1999) al resaltar que "entre más el espacio propio se vuelve exiguo, más se carga de aparatos y objetos. Se diría que es necesario que este lugar personal se haga más denso, material y afectivamente, para devenir en el territorio donde se arraiga el microcosmos familiar, el lugar más privado y querido"(p. 149). La población objetual del espacio permite la apropiación del mismo y por ende la consolidación de un vínculo emocional y afectivo con él; de ahí la relevancia de la triada sujeto-objeto-espacio en la construcción del universo simbólico doméstico.

Del mismo modo, en el espacio de la cotidianidad los objetos operan como signos de identidad cultural, social e individual; sus presencias y ausencias denotan particularidades de los sujetos que habitan un espacio: intereses, gustos, pretensiones, carencias y temores, "Un lugar habitado por la misma persona durante un cierto periodo dibuja un retrato que se le parece” (Certeau y Giard, 1999, p. 147). En ese sentido, la espacialidad se configura como un reflejo de las subjetividades implicadas en ella, en la que los objetos tendrían un papel preponderante al concretizar determinadas emocionalidades que responden, a su vez, a procesos socioculturales de los sujetos. 
Sin embargo, en los espacios domésticos contemporáneos resulta cada vez más difícil identificar otros rasgos de las subjetividades que lo habitan más allá de su afán de consumo. La intensificación del consumismo que caracteriza la época actual de globalización neoliberal, en la que la devastación productiva ha inundado el mercado de infinidad de mercancías, ha reconfigurado la relación con los objetos. Así, los interiores domésticos se han superpoblado de objetos con los que ya no se establecen vínculos afectivos y emocionales, pues estos ahora son solo mercancías que, en el marco de la hiperproducción han perdido su estatuto de singularidad. La saturación objetual terminó por borrar las particularidades materiales de los objetos al envolverlos en una amalgama amorfa e indistinta.

En El lenguaje de las cosas, Deyan Sudjic (2009) señala que:

Nunca tantas personas hemos poseído tantas cosas como ahora, aun cuando hagamos cada vez menos uso de ellas. Los hogares en los que pasamos tan poco tiempo están repletos de objetos: tenemos un televisor de plasma en cada habitación, sustituyendo a los aparatos de rayos catódicos, de moda hace solo cinco años; nuestros armarios están repletos de sábanas —últimamente hemos desarrollado un interés obsesivo por el número de pasadas de hilo que contienen-; apilamos montones de pares de zapatos en nuestros armarios; tenemos estanterías de discos compactos y cuartos llenos de videoconsolas y ordenadores; surtimos nuestros jardines de carretillas y todo tipo de aperos; poseemos aparatos de gimnasia con los que nunca hacemos ejercicio, mesas de comedor en las que nunca nos sentamos a comer y hornos de triple función en los que apenas cocinamos (p. 9).

En este fragmento, Sudjic, además de dar cuenta de la profusa población objetual de los espacios domésticos, deja entrever el modo en que ha operado la sociedad de consumo, en la que se consumen grandes cantidades de objetos que ni se requieren ni se usan. Moles (1971, pp. 9-10) argumentaba que la proliferación de los objetos se debía principalmente a tres causas: la tendencia adquisitiva de los sujetos, la producción en serie, que responde a unas demandas, y al consumo ostentatorio. Esta situación de consumo excesivo de objetos ha terminado por convertirse en lo que el mismo Sudjic denomina una epidemia de obesidad, que se da no solo por la obsolescencia de los productos sino también por las estéticas de diseño y las estrategias de marketing. En este contexto se hace necesaria una reinterpretación de la relación entre los sujetos y los objetos, pues en una sociedad de hiperconsumo, de fabricación de objetos-mercancías en serie, idénticos, sin particularidades, es inevitable la pérdida del vínculo con los objetos, ya que estos son simplemente reemplazables entre sí.

Precisamente, a este régimen desvinculante se opone la narrativa de González. En el corpus analizado, la materialidad objetual mantiene rasgos de singularidad y vínculos 
afectivos con los sujetos. De este modo, objetos como una cuchara, un reloj, unos lentes, un mueble o un motor adquieren una historia, un sentido, que se asocia a los modos en que se obtuvieron, los lugares de los que provienen, las temporalidades que convocan, los procesos vivenciales en los que estuvieron o las constelaciones de sentido que en sí mismos contienen. Así, en el barroco objetual doméstico, el objeto se agencia y se resemantiza.

\section{De hondas, libretas, camas y ataúdes}

En la construcción espacial que hace González en su narrativa parece alejarse de esa saturación objetual, tan presente en la vida contemporánea. Los interiores que representa en sus novelas están cargados someramente por objetos, distinguibles aún entre sí: un cuadro del niño Jesús de Praga, una lámpara de cristales, una hamaca, un acordeón o una revista del Reader's Digest desperdigada en el suelo. Los objetos se inscriben en un régimen de visibilidad particular y son reconocibles en el marco de los espacios domésticos a los que se circunscriben los relatos. Esto permite la configuración de escenarios cargados significativamente por una materialidad, en los que se pueden entrever modos de interacción específicos entre los sujetos y los objetos, que van desde la relación práctica y funcional hasta la estética y contemplativa.

En relación con los sujetos, los objetos son agentes articuladores de identidad, pues operan como marcas distintivas de su comportamiento y personalidad, y en este sentido también son factores determinantes en sus procesos de subjetivación. Ejemplo de ello son Elías y Jerónimo, personajes de La Historia de Horacio. El primero, hermano mayor de Horacio, y el segundo, hijo de este último. Elías, alter ego del filósofo Fernando González, es reflexivo, un meditabundo que siempre lleva consigo unas libretas en las que va anotando cada uno de los pensamientos y reflexiones que se le ocurren durante el día. Jerónimo, joven pícaro y vivaracho, siempre carga una honda con la que caza pájaros que luego diseca. Por una parte, la libreta y el constante ejercicio escritural en ella dan cuenta no solo del activo proceso reflexivo de Elías, sino también de la vitalidad de su pensamiento y de su práctica filosófica sostenida en la cotidianidad. Por otra parte, la honda de Jerónimo, y la práctica que lleva a cabo con ella, denota la personalidad violenta, egoísta e insensible del joven.

En la novelística de González priman los objetos artesanales sobre aquellos producidos en serie. Los espacios domésticos son constituidos de manera particular a partir de objetos realizados de manera artesanal, es decir, de un modo no industriali- 
zado. Por esto, los objetos poseen unas características de singularidad que aquellos elaborados en serie han perdido en el proceso de su producción masificada. Al respecto, señala Dorfles (1972) que esta sería la principal distinción entre estos tipos de objetos, artesanales e industrializados, en la que el primero "posee características estéticas que se revelan solo en el acto de la realización del mismo y que incluso pueden serle agregadas en el último momento por el particular y sensible 'toque' del artesano" (p. 58); por el contrario, en el segundo, "la cualidad artística está [...] implícita en el diseño original, o al menos en el modelo ejecutivo, que constituye la matriz de todas las sucesivas formas de la serie" (p.58) de objetos producidos exactamente iguales entre sí.

En Los caballitos del diablo los faroles artesanales distribuidos por la casa recién reformada van constituyendo el lugar como propio. Él, protagonista de la novela, decoró diferentes partes de la casa con faroles que le compró a Ángel, un primo suyo que los fabricaba con cobre y “les ponía vidrios antiguos de colores” (González, 2012, p. 20). Así, la casa recién adquirida va tomando forma a partir de la disposición de estos objetos cuya ubicación consagra los nuevos lugares, como sucede cuando se reforma el baño o se hace un camino de piedras con un entejado. Estos son una parte determinante del espacio doméstico en la novela, que es coherente con la manera artesanal en la que la casa se va expandiendo en su singularidad de acuerdo con unas necesidades particulares, junto a las pinturas y los mosaicos hechos por Pilar, la otra protagonista de la historia.

El trabajo manual, predominante en la espacialidad rural, ámbito privilegiado de la narrativa de González, ${ }^{3}$ es una práctica recurrente en la cotidianidad de los personajes de sus relatos. En sus textos el hacer manual está asociado no solo al trabajo del campo, vinculado a dicha espacialidad, sino también a la producción de objetos funcionales y/o artísticos. A propósito de la definición que refiere Dorfles (1972) sobre los objetos, "cosas materiales debidas a una manipulación directa de cualquier sustancia presente a nuestro alrededor que conduzca a la formación de algo distinto de lo que existía con anterioridad" (p. 55), en Primero estaba el mar resulta evidente el modo en que la materia es transformada por los sujetos para producir objetos.

En esta primera novela de González hay una materialidad que se manipula en diferentes momentos de la narración y va marcando la pauta de los acontecimientos. Cuando recién se mudan a la casa en una playa de la costa pacífica J. y Elena, luego

Véase Primero estaba el mar, La historia de Horacio, Los caballitos del diablo, Abraham entre bandidos, La luz difícil, Niebla al mediodía y Las noches todas. 
de un extenso proceso de limpieza, comienzan a proyectar su vida allí. El primer gesto necesario para constituir la domesticidad del lugar, para poder nombrarlo "hogar" es hacerse de una cama. Esta es la primera labor encargada a Gilberto:

[Para hacerla] se utilizaron unas tablas gruesas y sin pulir que había debajo del corredor. Eran largas y J. dijo: - Hágala de dos por dos, Gilberto.

El hombre abrió mucho los ojos. En su vida había oído de una cama tan grande.

El resultado fue un lecho más que doble, sólido como un altar mayor. Era una especie de planchón con testeros, al que habrían de comprar cuatro colchones sencillos, dos para cubrir su extensión y otros dos para que quedara doble, y que jamás iría a ser lo confortable que ellos habían soñado -pues los colchones que se conseguían en Turbo eran fibrosos y compactos-. La cama, no obstante, se veía imponente. Los catres en que dormirían hasta la llegada de los colchones parecían frágiles veleros al lado de semejante trasatlántico (González, 2011a, p. 42).

Específicamente, la cama es un pilar central en la configuración del universo doméstico; de esto da cuenta Michelle Perrot (1991) cuando señala que "tener una cama de madera en lugar de un jergón equivale a sentirse instalado: una obrera, hacia 1880, trató de matar a su compañero porque había gastado el dinero ahorrado para la compra de una cama, lo que habría significado la consolidación de la pareja” (p. 21). Este objeto doméstico pone de relieve el valor de los objetos como agentes constituyentes del universo cotidiano. En él, estos "desempeñan un papel regulador [...], en ellos desaparecen muchas neurosis, se recogen muchas tensiones y energías en duelo" (Baudrillard, 1969, p. 101). Así, en esta narración de González, la cama se configura no solo como un símbolo que evoca esa conyugalidad burguesa de la que habla Baudrillard (1969), sino que también funciona como símbolo del descomunal proyecto de J. y Elena de abandonar la vida en la ciudad para vivir en una aislada zona costera rodeada de selva, a cuatro horas y media en lancha del pueblo más cercano, pese a desconocer los modos de subsistencia y supervivencia de la región. Un proyecto desmedido al cual tratan de adaptarse, pero que termina por superarlos fatalmente.

En este sentido, la cama opera como metáfora del relato existencial de los sujetos, pues “jamás iría a ser lo confortable que ellos habían soñado". De esta forma, la cama se constituye como ese objeto-símbolo al que alude Milton Santos (2000), al señalar lo que el concepto de objeto representa para Baudrillard, esto es, "aquello que el hombre utiliza en su vida cotidiana, sobrepasa el contexto doméstico y, presentándose como un utensilio, también constituye un símbolo, un signo" (p. 57). Un signo, en este caso, en el que se cristaliza la fatalidad de lo narrado. 
En concordancia con lo anterior, la materialidad de la cama va a transfigurarse concretamente en un objeto fatídico hacia el final de la novela al convertirse en un ataúd. Tras el asesinato de J., por parte de Octavio, su cuerpo pasa varios días expuesto en una mesa, hinchándose, hasta la llegada de uno de sus hermanos de Medellín. Este, tras su llegada, ordenó con premura a Gilberto que hiciera un ataúd con la madera de la cama, quien la desarmó y seleccionó las mejores tablas, mientras buscaba clavos, "pero clavos tampoco había. Gilberto enderezó entonces los que había sacado de la cama y empezó a clavar el ataúd. El resultado fue un cajón grande y feo, que parecía hecho para cualquier cosa menos para meter un muerto" (González, 2011a, p. 100). El objeto-cama, que abre la vida común, la cotidianidad doméstica, se trasforma para cerrar la narración, y su materialidad se transubstancia como significante de la fatalidad, de modo que el objeto absorbe el impacto del devenir accional. En esta novela, la concretización de la materia en lo objetual marca los ciclos de la diégesis y constituye así un eje central de la narración.

La relevancia de los objetos en esta primera novela de González no solo está dada por la cama, sino también por otros elementos como la máquina de coser y el baúl de libros con los que J. y Elena llegan a su nueva vivienda:

El equipaje iba arriba, en el techo del bus. Eran dos maletas de cuero con la ropa de ambos, un baúl cuadrado con los libros de él, y la máquina de coser de ella. Todo viajaba entre racimos de plátano, bultos de arroz, paquetes grandes con panelas - envueltos en hojas secas de plátano-y otras maletas (González, 20ıra, p. 9).

Estos objetos marcan el tránsito de la ciudad a la vida rural, son objetos que, como deja ver la narración, resultan ajenos al contexto cotidiano al cual ellos se aproximan. Sin embargo, la función que estos tienen es la de ser marcas identitarias, al operar como talismanes que afianzan una subjetividad frente al devenir caótico de lo desconocido; en suma, son materialidades a las que se aferran los sujetos.

En línea con esto, los objetos se erigen como un refugio para los sujetos, es decir, como un hogar en sí mismos. A esto se refiere la filósofa Françoise Collin (1994) cuando plantea que muchas personas, “cada vez más, viajan, transportando 'su hogar' en una bolsa, una maleta, un maletín. En cierto modo, ahora llevamos nuestra casa a la espalda como el caracol” (p. 234). Los objetos como parte estructurante de un espacio doméstico son parte de una noción de existencia individual, a la cual los sujetos se aferran en los constantes desplazamientos contemporáneos: 
[...] en el desfile rápido de paisajes y personas, cada uno graba alguna marca que le recuerde a sí mismo, para identificarse y orientarse. El camionero tiene su fetiche o su fantasma sobre el parabrisas, el viajero coloca su portarretrato sobre la mesilla de una habitación de hotel anónima, confiriéndole así un nombre (p. 234).

En la interacción cotidiana con el objeto este se carga con una semántica existencial que, al ser transportada, puede o no implantar sus significaciones en un nuevo escenario, lo cual dependerá de las dinámicas propias de los objetos y los sujetos en ese nuevo contexto. La máquina Singer y los libros de literatura universal y temáticas agrícolas con los que viajan J. y Elena son los signos que definen una vida anterior.

En el nuevo contexto, estos objetos quedan inoperantes: la máquina se descompone al llegar y los libros, que antes había sido muy usados, comienzan a empolvarse en la biblioteca "con ocasionales lagartijas trepándose a sus lomos, mientras bandadas de alharaquientos loros pasaban sobre la casa, o negros descalzos, con un machete terciado al hombro, pasaban por la playa silbando y dejando un olor a tabaco en el aire" (González, 2011a, p. 34). En este territorio al que ahora se circunscribe la existencia de los sujetos, los objetos mencionados se vacían de significaciones precedentes y se cargan con unas nuevas, que en este caso se reducen a su inoperancia contextual. Esto lo enuncia el ayudante de Julito, el lanchero, mientras carga el baúl y le pregunta a J. si lo que lleva ahí es un cadáver (González, 2011a, p. 27). En esta nueva territorialidad la agencia de estos objetos no logra actualizarse; en este sentido es significativo el contraste que hace el narrador entre el peso muerto de los libros y la vitalidad del territorio, estos obsoletos, mientras la vida los circunda: lagartijas, loros y negros silbando mientras impregnan el aire con olor a tabaco.

\section{Desterritorializar el libro y la lectura}

En el marco general de la novelística de González hay algunos objetos que figuran como constantes: libros, pinturas y antigüedades. Estos objetos no solo se asocian a unas espacialidades domésticas determinadas, sino que también definen prácticas activas de los sujetos: la lectura y el coleccionismo. De este modo, los objetos se articulan como ejes dinamizadores y constituyentes de los ritmos del habitar doméstico.

En primer lugar, en las novelas del autor los libros se presentan como una constante que hace parte del repertorio material de varios personajes. En Primero estaba el mar, como se mencionó, J. viaja con un baúl de libros; en Para antes del olvido, el 
hermano de León guarda libros que restaura en una caja fuerte; en Los caballitos del diablo, Él construye una biblioteca en "la casa de abajo"; en Temporal, la cabaña de Javier está repleta de libros desperdigados por el suelo, y en Niebla al mediodía hay libros hasta en los baños de la casa de Julia. En esta invariable presencia de los libros en la obra de González, el autor expone no solo una noción de espacio doméstico burgués, sino también una idea particular de sujeto letrado.

En las novelas analizadas, los libros y las prácticas directamente asociadas a ellos no están limitados a un único espacio doméstico; más bien tales objetos y prácticas se articulan en el espacio de manera transversal. Si bien en algunas novelas aparecen espacios funcionales para la lectura y la conservación de los libros, como la biblioteca, estos no constituyen la espacialidad principal a la que necesariamente se circunscriben.

En las novelas, los libros se apropian del espacio de dos formas: la primera, de un modo estructurado, funcionalizado y organizado, esto es, en la biblioteca; y la segunda, de manera dispersa en cualquier lugar del espacio doméstico. La prevalencia de uno u otro de estos modos del aparecer del objeto y de agenciarse en la espacialidad dan cuenta de las subjetividades que habitan un espacio y los vínculos que estos establecen con el objeto-libro.

Las bibliotecas, como espacio configurado para los libros, aparecen, paradójicamente, como propiedad de personajes que no tiene un estrecho vínculo con la lectura: Él, en Los caballitos del diablo, solo acude a ella esporádicamente cuando necesita estar solo; Raúl, que ha heredado la colección completa de libros de su padre, no frecuenta su biblioteca en Niebla al mediodía, a diferencia de Sofía, su pareja, quien día a día devora cada uno de los libros que la componen; lo mismo ocurre con Javier en Para antes del olvido, quien posee y ha ido construyendo una biblioteca con ejemplares que ha mandado a restaurar, pero es su hermano, León, quien se apropia de los libros que la componen, y los deja deshojados y llenos de rayones tras sus lecturas desordenadas y violentas.

De ahí que la posesión de este objeto-espacio no implique una interacción activa por parte de quien lo posee. Las bibliotecas como espacios figurantes, al dar cuenta de este tipo de distanciamiento con el objeto, ponen en relato un quiebre con un modelo de espacio doméstico. Así, lo que esta particular relación de inactividad pone de manifiesto, en la novelística de González, es el agotamiento del imaginario de prestigio burgués asociado a la dicotomía objeto-espacio/libro -biblioteca, al exponer el trasfondo de interacción vacía e inexistente. 
Por el contrario, en la dispersión de los libros en espacios carentes del orden impuesto por la biblioteca se establecen interacciones más activas, de lecturas desaforadas y frenéticas por parte de quienes los poseen y disponen de ellos en tales espacios. Ejemplos de esto los encontramos en personajes como Javier, uno de los protagonistas de Temporal, y en José, uno de los hijos de Abraham en la novela Abraham entre bandidos. En el caso de Javier, que "lee como un putas" (González, 2013, p. 131), los libros están desperdigados por todas partes: "en la sala, en las tres habitaciones de la casa e incluso en el baño y la cocina, no estaban en bibliotecas sino en pilas de diez o quince libros, como si se tratara de una especie de depósito o bodega" (p. 15). Asimismo, en la casa de José, quien desde muy joven había comenzado a leer "en cantidades industriales", las "pilas de libros y revistas llega[ban] casi hasta el cielo raso en algunos de los cuartos” (González, 2010, p. 142). El caos de la dispersión de los libros es la respuesta a una interacción activa y desbordada con el objeto, que no se restringe ni a temas ni intereses específicos, ni a pretensiones o postureos intelectuales de los sujetos. Los libros se toman la espacialidad denotando un valor en el marco de una cotidianidad determinada, se inscriben como huellas en el espacio y dan cuenta de los ritmos de un habitar particular.

La lectura por su parte aparece también como una práctica desterritorializada en el espacio. En el afán lector de algunos de estos personajes representados en las novelas, la cocina, la terraza, un kiosco, un corredor, una hamaca en medio de la sala o el baño se constituyen como espacios resignificados por las prácticas lectoras. León, en Para antes del olvido, leía en la terraza de su casa, junto a los conejos y las gallinas que criaba:

Ciertos anocheceres, cuando León se quedaba largas horas en la terraza leyendo bajo un bombillo que colgaba de un cable, miraba de vez en cuando los ojos rojos de sus conejos; otras veces, mientras se perdía interminablemente en la maraña de sus propios pensamientos, el ruido que las gallinas emitían le había traído ráfagas momentáneas del bienestar intestinal que los entendidos conocen como "ser feliz" (González, I987, p. 43).

En la no delimitación de un espacio para la lectura o la disposición del objeto-libro hay una noción de espacio doméstico y de sujeto propuesta en la narrativa de González. En cuanto al primero, la deslocalización de los objetos en la representación apuntala una noción de espacio doméstico multifuncional, contrario al propuesto por la arquitectura moderna, en la que cada espacio tiene unas funcionalidades determinadas. Así, los espacios que se privilegian en la representación de la lectura y como estancia de los libros ya no son la habitación como espacio para la intimidad lectora, como se- 
ñalaba Perrot (2011, p. 89), ni tampoco la funcionalidad del estudio o de la biblioteca. En González hay una descolocación del objeto y de la práctica en el espacio, lo que termina por expandir las experimentaciones sensibles de los sujetos, como da cuenta el fragmento anterior referido a León, de manera que se articula representacionalmente una práctica de lectura que, en vez de aislar, integra al sujeto con su entorno vital.

En este mismo sentido, se construye la noción de un sujeto lector que, sin pretensiones de intelectualidad, al dejarse llevar por su hábito, resignifica funcionalmente los espacios. El lector representado en González es desbordado por su pasión sin caer en el postureo anonadante del poseedor o del que se explaya en su conocimiento y lo derrocha. Esta es la principal característica que distingue a personajes como Javier, León, Sofía o José con respecto a Julia, una de las protagonistas de Niebla al mediodía, poeta en la que destaca una elevada autopercepción de sí misma como intelectual y como persona altamente sensible.

Una importante figura que contrasta con Julia y encarna esa idea de lector que interesa representar a González es la de José Jesús, personaje mítico que aparece en dos novelas del autor, en Para antes del olvido (González, 1987, pp. 94, 102, 179, 215) y en La historia de Horacio (González, 2001b, pp. 28, 192). José Jesús fue un hombre que pasó su vida

[...] sentado en una mecedora leyendo libros y dejándose caer la ceniza del tabaco en el chaleco y los pantalones.

— ¿Nunca trabajó? - preguntó León. Ya había oído la historia otras veces; siempre le llamó la atención el modo como la vagancia había encontrado ejemplares casi puros (él mismo, para no buscar mucho) en cada generación de pujantes antioqueños.

-Olía a tabaco desde lejos. Él le enseñó inglés a Alfonso. Y vaya, mijo, a saber dónde aprendió inglés José Jesús.

Josefina contó otra vez cómo su tío, que era alto, flaco y había muerto de sesenta y ocho años, se asomó una vez a una jaula para silbarle con cariño al sinsonte, y el animal, atraído por su propio reflejo en las gafas del hombre, le pegó un picotazo que le rompió el cristal y le vació el ojo derecho. Apenas se curó, se puso un parche negro y siguió leyendo con el ojo izquierdo (González, 1987, p. 94).

En su entrega a la lectura contemplativa y desbordada, José Jesús encarna una figura única que articula su existencia más allá de los ritmos impuestos por un medio social. Su lectura desinteresada e "infinita" configura un modo de habitar el mundo que se abstrae al afirmar la negatividad del no hacer. Esa misma negación se afirmaba Gonzalo Arango (1974) cuando señalaba: "No todo es Hacer, Medellín. También No-Hacer es creador, pues no sólo de hacer vive el hombre” (p. 122). En este punto, la representación de este personaje 
y de su interacción cotidiana con los libros amplía la semántica de la lectura, al agregar la “vagancia” y el ocio como prácticas necesariamente vinculadas a esta, prácticas que contrastan fuertemente con ese imaginario del hacer constante, que define hoy la academia neoliberal y que, como imaginario, ha definido largamente la cultura antioqueña.

\section{Coleccionismo: de afectaciones y afectos materiales}

Junto a la práctica de la lectura, en la novelística de González se dan otras importantes prácticas que se definen por un tipo de relación particular con los objetos, estas son las del coleccionismo y la acumulación. Específicamente, estas prácticas y modos de relación con los objetos resultan particularmente visibles en dos novelas: Los caballitos del diablo y La historia de Horacio. En ellas, los personajes protagonistas Él y Horacio, respectivamente, acumulan o coleccionan algún tipo de objetos, desde antigüedades y pinturas hasta muebles y camas, además de otros objetos funcionales que son extraídos de su contexto operativo.

La principal diferencia entre estas dos prácticas radica en la relación que en ellas establecen los sujetos y los objetos. En la acumulación, al sujeto "no le interesa lo singular sino la masa y reúne todo a ciegas para satisfacer una sed imaginada actual o futura" (Sánchez, 1999, p. 16). Así, en el ejercicio de acumular, los objetos son indistintos, pues pierden su especificidad al convertirse en parte de un todo amorfo. Por el contrario, la práctica coleccionista se fundamenta en una conciencia constante de su hacer, de modo que hay una sistematicidad que la regula. En ella cada objeto desde su peculiaridad se articula como parte estructurante de una colección.

En Los caballitos del diablo, la "casa de abajo" es un espacio abierto a la acumulación. Después de la construcción de este lugar las paredes se llenaron de estantes

[...] donde él siguió acumulando libros y objetos: sextantes, brújulas de cobre como cascos de caballo, panzones muñecos precolombinos de barro con orejeras de oro, balsas de oro cargadas de ofrendas para los dioses, lámparas de vidrio con figuras de tulipanes de colores, faroles de los que se usaron en los coches de caballos y estatuas en bronce de mujeres desnudas, las calaveras que había subido de la biblioteca y entre libros de todos los tamaños y calidades (González, 2012, p. 87).

Allí, Él va depositando las cosas que encuentra o que comienzan a amontonarse en su finca: las calaveras de perros que encuentra al excavar, los frascos de conservas, los corozos secos, pieles de conejo y el vino fermentado de naranja que él mismo preparaba. En este espacio los objetos y las cosas se aglutinan de manera desordenada y caótica. 
Por su parte, el garaje en La historia de Horacio es un símbolo de coleccionismo. En este lugar, Horacio guarda diversos objetos, como aquellas “antigüedades que sólo estaría dispuesto a vender después de resistir hasta el final, cuando ya no hubiera para comer o pagar los colegios de los niños, y casi por sobre su cadáver"(González, 2011b, p. 11). Este personaje mantiene un fuerte vínculo sensible con los objetos que colecciona; de ellos "le gustaba el olor de la madera vieja, el bronce oxidado, del cobre" (p. 10), por ejemplo. En la práctica de coleccionar hay una sensibilidad y una historia implicada en cada objeto que el coleccionista posee, de modo que cada uno de ellos adquiere una identidad particular en el marco de la colección misma.

Walter Benjamin, en su texto "Desembalo mi biblioteca", reflexiona sobre el arte de coleccionar con motivo de su instalación en Berlín en 1931. Allí, el filósofo alemán diserta sobre la particular relación que establece el coleccionista con el objeto coleccionado, señala que en la colección los objetos se configuran en sí mismos como “escenario o teatro de su destino" (Benjamin, 2012, p. 34), pues en ella, estos adquieren un valor afectivo que relega su valor funcional.

En este mismo sentido, sostiene Yvette Sánchez (1999) que los objetos "al ser arrancados de su contexto original para convertirse en objetos de mera contemplación, se alejan de su función primaria” (p. 16). En este desplazamiento de lo funcional se da un proceso de transubstanciación del objeto a partir del lazo afectivo que se establece con él. Horacio conserva en cajas en su garaje, lámparas de cristales franceses, porcelanas de bacantes, sujeta libros de bronce, cuadros de santos y hasta un automóvil Volkswagen; todos estos objetos no operan en el espacio de la funcionalidad, es decir: no transportan, no iluminan, no decoran. Así, los objetos son desplazados del imperio de lo funcional hacia un régimen de estesis abierta.

De igual forma, en el texto El coleccionista apasionado: una historia intima, Philipp Blom (2013) sostiene que "sea lo que sea lo que coleccionamos, tenemos que matarlo" (p. 577); de esta manera hace referencia al proceso de desterritorialización que opera en los objetos coleccionados, ya que al ser "apartados de su entorno habitual, de sus funciones y de su circulación, y colocados en un entorno artificial, privados de su antigua utilidad" (p. 578) se convierten en objetos muertos para el mundo. Igualmente, en el Libro de los pasajes, Benjamin (2005) plantea justamente que al coleccionar el objeto es liberado "de todas sus funciones originales para entrar en la más íntima relación pensable con sus semejantes” (p. 223). La colección, siguiendo a Ben- 
jamin, se establece entonces como un sistema orgánico de reconfiguración del objeto en el que este logra agenciarse más allá de la racionalidad hegemónica antropocéntrica.

En la dinámica del coleccionismo, la relación sujeto-objeto deviene fundamentalmente contemplativa; en ella, el sujeto que colecciona encuentra una especie de plenitud. La colección constituye un entorno de familiaridad, pues para el coleccionista este es el espacio que representa su máxima expresión como sujeto-individuo y, por ende, se siente pleno al habitarlo. Este lugar se torna entonces como un espacio de reflexión, compleción y sosiego. De ahí que ante la sensación de muerte que lo agobia, ante las presiones económicas y las dificultades familiares, Horacio se refugie en el garaje:

[...] abrió el Volkswagen y se dejó inundar con placer por el olor a caucho encerrado y a tapicería, olor que tenía un toque ácido y remoto de líquido de baterías. Mío, pensó. Dos mil kilómetros apenas. Cuarenta y dos mil cagados pesos. El único carro en el mundo que no necesita agua, que no tiene radiador. Hitler lo mandó a hacer para la campaña del desierto. "Háganme un carro que no necesite agua, que no tenga radiador, hijueputas”, dijo, y el carro fue hecho (González, 2011b, p. 24).

Asimismo, en la práctica coleccionista cada objeto evoca una historia particular y, a la vez, un pasado emocional y sensible. En este contexto el objeto se articula como un umbral espaciotemporal en la medida en que se establece desde el presente como un artefacto evocador de un pasado y activador de una proyección de futuro. En ese sentido, el coleccionar se constituye como "una forma de recordar mediante la praxis" (Benjamin, 2005, p. 223), en la que el objeto representa un talismán que posee una narrativa propia en relación con el sujeto coleccionista.

A modo de cierre se puede afirmar que los objetos presentes en las novelas analizadas de González tienen la función de configurar de manera articulada unas nociones de espacio doméstico y de sujetos. El espacio representado por el autor, en relación con los objetos, es uno que se resiste a las condiciones de una época moderna en la que estos, al ser producidos en serie, abundan y saturan la espacialidad doméstica. Por el contrario, en el sobrio espacio representado priman los objetos artesanales que, al ser hechos de manera manual, dan cuenta, por una parte, de una capacidad de agenciamiento de los sujetos en la transformación de la materialidad objetual de su entorno y, por otra, de un grado de singularidad que poseen los objetos en sí mismos, el cual los configura como dispositivos articuladores de unas tramas narrativas.

Asimismo, la preponderancia de determinados objetos en las novelas (libros y objetos de colección) visibilizan ritmos particulares del habitar de los sujetos en la 
espacialidad doméstica. Así, espacios asociados a los libros como las bibliotecas o el estudio se muestran obsoletos como espacios de conservación y de práctica activa de lectura. Las deslocalizaciones del objeto-libro y de las prácticas de lectura responden a sujetos que, sin pretensiones intelectuales, configuran otro tipo de dinámicas interaccionales desterritorializadas que, integrando los sujetos, los objetos y el medio, afirman la negatividad del no hacer.

Del mismo modo, en las novelas se establece otro vínculo importante con los objetos a partir del gesto coleccionista. En la práctica del coleccionismo se constituye una significativa relación vinculante entre el sujeto y el objeto que, mediada por una sensibilidad y unos afectos particulares, produce unos modos de interacción que visibilizan no solo unos ritmos del habitar, sino también una determinada estructuración del espacio doméstico. De esta forma, los sujetos y objetos se afectan mutuamente en una semiosis que resemantiza la existencia de ambos.

En general, en la novelística de González las prácticas que se establecen en relación con los objetos concretizan los valores asociados a una noción de sujeto que propone el autor. Así, a través de ellas se articula un sujeto que se resiste tanto a las prácticas consumistas en las que el objeto es vaciado de cualquier significación por la indiferencia acumulativa, como a las prácticas ostentatorias y de postureo asociadas a determinados objetos-prácticas. Al mismo tiempo, este sujeto propende al apasionamiento, la sensibilidad y la contemplación gracias a las prácticas activas que mantiene de apropiación y afectación mutua con la materialidad circundante.

\section{Referencias bibliográficas}

Arango, G. (1974). Obra negra. Buenos Aires: Cuadernos Latinoamericanos.

Baudrillard, J. (1969). El sistema de los objetos. México: Siglo xxi.

Benjamin, W. (2012). Desembalo mi biblioteca: el arte de coleccionar. Barcelona: Centellas.

Benjamin, W. (2005). Libro de los pasajes. Madrid: Ediciones Akal.

Blom, P. (2013). El coleccionista apasionado: una historia intima. Barcelona: Anagrama.

Certeau, M. de, y Giard, L. (1999). Espacios privados. En M. de Certeau, L. Giard y P. Mayol. La Invención de lo cotidiano 2. Habitar, cocinar (pp. 147-150). México: Universidad Iberoamericana. Recuperado de https://bit.ly/2HSJTUX [31.10.2020]

Collin, F. (1994). Espacio doméstico. Espacio público. Vida privada. En Ciudad y Mujer (pp. 231-237). Madrid: Seminario Permanente Ciudad y Mujer. 
Dorfles, G. (1972). Naturaleza y artificio. Barcelona: Editorial Lumen.

González, T. (1987). Para antes del olvido. Bogotá: Plaza \& Janes.

González, T. (2010). Abraham entre bandidos. Bogotá: Alfaguara.

González, T. (2011a). Primero estaba el mar. Bogotá: Penguin Random House.

González, T. (2011b). La historia de Horacio. Bogotá: Punto de Lectura.

González, T. (2012). Los caballitos del diablo. Bogotá: Punto de Lectura.

González, T. (2013). Temporal. Bogotá: Alfaguara.

Moles, A. (1971). Objeto y comunicación. En Los objetos (pp. 9-35). Buenos Aires: Tiempo Contemporáneo.

Perrot, M. (1991). Formas de habitación. En P. Ariés, y G. Duby. Historia de la vida privada. La Revolución francesa y el asentamiento de la sociedad burguesa (Tomo 8, pp. 9-26). Madrid: Taurus.

Perrot, M. (2011). Historia de las alcobas. México: Fondo de Cultura Económica, Ediciones Siruela.

Sánchez, Y. (1999). Coleccionismo y literatura. Madrid: Cátedra.

Santos, M. (2000). La naturaleza del espacio. Barcelona: Editorial Ariel.

Sudjic, D. (2009). El lenguaje de las cosas. Madrid: Turner. 